\title{
LA ARQuitectura del Estereotipo Cultural en el Cine del RéGimen FRANQUISTA: EL "GALAIQUISMO"
}

Beatriz Busto Miramontes Universidade de Santiago de Compostela, A Coruña, España ${ }^{1}$

\begin{abstract}
"Galaiquismo" es un término inspirado en el concepto "Orientalismo" de Edward W. Said para reflexionar sobre cómo NO-DO, organismo de propaganda cinematográfica del régimen franquista, elaboró un discurso de representación cultural sobre Galicia y lo gallego, haciendo un uso folclorizado de la cultura. Muchos de los materiales NO-DO hacen referencia explícita a lo folclórico, elaborando asi un mapa territorial en el que el estereotipo se convirtió en el principal indicador de representación cultural y la invención en la principal herramienta de promoción turística. NO-DO se convirtió en un poderoso aparato del régimen, produciendo un discurso ejecutado desde "fuera" hacia "dentro" en un claro ejercicio de poder vertical (arriba/abajo) que definia la cultura en estampas folclóricas que evidenciaban una mirada colonial del centro sobre las periferias, negando la posibilidad a los pueblos retratados en las imágenes de dialogar o discutir la parábola que se producía de si mismos.
\end{abstract}

Palabras clave: folclorismo, poder, representación, etnicidad, cine

\section{INTRODUCCIÓN}

NO-DO, acrónimo de Noticiario Documental, fue el organismo de propaganda cinematográfica del régimen franquista y en él y a través de él se inventaron y promocionaron gran número de arquetipos culturales. Eso convirtió a NO-DO en un potente aparato de representación. De los 6000 materiales del archivo NO-DO muchos hacen referencia explícita a la cultura de los pueblos que constituían España, elaborando un mapa en el que el tipismo y la homogeneización se convirtieron en las herramientas principales de representación.

1 Grupo Galabra. Escola Municipal de Música de Santiago de Compostela. Universidad Autónoma de Madrid (Madrid, España). Contacto: beabustom@gmail.com. 
Galaiquismo es un término que se inspira en el concepto de Orientalismo de Edward W. Said para reflexionar sobre cómo NO-DO elaboró un discurso de representación sobre Galicia haciendo un uso específico de la cultura estereotipada. Este discurso de representación de Galicia se producía y ejecutaba en un claro ejercicio de poder vertical y violencia simbólica que dejaba definida la cultura gallega en estampas representativas cuyo indicador discursivo principal fue el estereotipo.

El medio por el cual se concretó este ejercicio fue el cine de NO-DO, cine en el que se negaba la posibilidad de que Galicia dialogase o discutiese esa imagen que se producía de ella.

Esta representación galaiquista de Galicia y lo gallego tuvo severas consecuencias políticas de cara el futuro puesto que, produjo, definió y representó hasta tal punto que los tipos folcloristas desarrollados han incidido notablemente-de manera transversal; colectiva e individualmente - en la forma en la que Galicia se piensa a sí misma y en la manera en la que esta, hoy en día, produce representación en el marco de un sistema turístico capitalista que tiende a mercantilizar los elementos etnicitarios reduciéndolos a "tipos" consumibles a la venta.

\section{APUNTES PARA UN ACERCAMIENTO A NO-DO}

NO-DO, se creó por acuerdo de la Vicesecretaría de Educación Popular del 29 de septiembre 1942 como un servicio de difusión de noticiarios y reportajes "con el fin de mantener, con impulso propio y directriz adecuada, la información cinematográfica nacional" (Tranche y Sánchez-Biosca 2006: 13).

La creación de un organismo como NO-DO no fue fruto de un interés informativo. E1 proyecto cinematográfico se puso en marcha con una clara intención:

NO-DO surge como un mecanismo para controlar y centralizar la información audiovisual, del mismo modo que ya lo habían hecho otros regímenes totalitarios. Por tanto, de aquí podría inferirse a priori que, junto a esa labor de control, el Organismo tuvo que ser cauce de expresión de las consignas oficiales, de las estrategias propagandísticas del Régimen (Ibid:: 179).

Se le atribuyó la exclusividad de la producción de noticiarios, y se decretó la obligatoriedad de su exhibición en pase previo a la proyección. Su emisión comenzó el primer lunes de 1943, y así se mantuvo durante los treinta y tres años siguientes, en todo el territorio nacional, posesiones y colonias; hasta el 22 de agosto de 1975 cuando, por orden del Ministerio de Información y Turismo, se suprimía la obligatoriedad de su proyección. A partir de enero de 1976, la misma pasaba a ser voluntaria y su producción se suprimiría definitivamente en el año 1981.

Mientras cualquier publicación en España debía someterse a una doble tijera-la política por un lado y la eclesiástica por otro- NO-DO se publicaba exactamente como se postproducía. No se consideró que hiciese falta un control censor sobre las imágenes de NO-DO puesto que su cine era claramente cine de Estado; era un organismo en el que la censura no era necesaria.

[... N NO-DO no solía recibir consignas estrictas de signo ideológico y, desde luego, jamás se transmitían estas por escrito. No cabe duda de que sus artífices conocían las predilecciones de los gobernantes e intentaban satisfacerlas, pero esto no debiera ser identificado como un control riguroso. En suma, el estilo NO-DO, 
independientemente de su empeño ideológico, el cual se fue desdibujando con los años, respondió a la obra de un equipo de profesionales que practicaban una hábil autocensura [...] (Tranche y Sánchez-Biosca 1993: 51).

NO-DO produjo varios modelos diferentes de entregas audiovisuales; diversos materiales con diferente temporalidad: Noticiarios, Documentales y Revista Imágenes.

Los Noticiarios eran materiales de 10 minutos en los que se exponían, sin aparente orden jerárquico, noticias cortas variadas que más que informar distraían y vertían propaganda del Régimen.

Los Documentales pretendían ser una entrega diferente de la anterior. Su duración podía alcanzar una hora y su proyección no tenía por qué ser de carácter nacional. En un principio fueron en blanco y negro, pero a partir de los años sesenta se empezaron a producir en color.

La entrega semanal de la serie Imágenes podía variar en su duración y solía cubrir eventos tales como la Semana Santa, el mundo del circo, visitas de personalidades, funcionamiento de industrias, temas relacionados con el turismo, etc. Su proyección tampoco era extensiva a todo el territorio español.

\section{LA ARQUITECTURA DEL ESTEREOTIPO. EL GALAIQUISMO.}

"Galicia é húmida e verde, mais non é un verxel" (Murado 2013:18) Con esa frase, y tantas otras, Miguel-Anxo Murado deconstruye uno por uno los tópicos relacionados con Galicia y lo gallego, pasando desde esa idea del paisaje inalterado a la queimada o el Camino de Santiago, en una suerte de arqueología de la historia de los tópicos. Helena Miguélez-Carballeira analiza también en Galiza, um povo sentimental? cómo el uso estereotipado del esencializado sentimentalismo gallego fue una estrategia discursiva de dominación colonial de Galicia frente a España. Es uno de los pocos trabajos, hasta la fecha, que han interpretado la relación política-territorial entre España y Galicia teniendo en cuenta la crítica poscolonial, analizando el estereotipo concreto del sentimentalismo como una herramienta de dominación, control y subalternización (Miguélez-Carballeira 2014). Xoán González Millán lo hacía también en su libro Resistencia cultural e diferencia histórica: a experiencia da subalternidade (González Millán 2000). Este artículo se encuentra en esa misma línea de argumentación teórica, considerando que el ejercicio cinematográfico de NO-DO creó una imagen subalternizada de Galicia y para ello se sirvió de la constante repetición de estereotipos (entre ellos el del sentimentalismo, pero no solo) como estrategia principal de dominación simbólica, valiéndose de la imagen cinematográfica y del potencial de representación que la misma posee.

En el año 1951—en plena fase nacional/catolicista del régimen-NO-DO produjo un documental en blanco y negro de 59 minutos de metraje titulado "Galicia y sus gentes. Ayer y hoy de las tierras meigas". Fue dirigido por Alberto Reig Gonzalbes y Cristian Anwander y es el único largometraje de NO-DO sobre Galicia con intención documentalista. El film abre con un primer plano de la rueda de un carro girando por un escenario rural con el fondo musical de la cantiga "Airiños, airiños, aires". Ese primer plano avanza todo el desarrollo posterior: un viaje entre vacas, muiñeiras, iglesias, hórreos, mitos construidos y paisajes. Fue uno de los films analizados en la muestra de $\mathrm{M}^{\mathrm{a}}$ Soliña Barreiro, referenciado en su comunicación Paysage et 
émigration: une anthropologie visuelle de l'espace galicien dans le cinéma du réel. Barreiro argumenta en ese trabajo cómo el paisaje idealizado, congelado e irreal de Galicia se muestra en la imagen cinematográfica como un continuum de representación.

En analysant une vingtaine de films on remarque des répétitions d'un même type de prises et de paysages caractérisés par une temporalité en suspens, figée. On trouve beaucoup de prises ouvertes et frontales de la nature, des principaux monuments, des rías gallegas calmes et de la mer féroce, de l'architecture assimilée au paysage, des paysans et des marins. Les prises et le montage sont archaïques ; l'expérience du territoire vécu n'est pas montrée. Ce genre de représentation cinématographique vise la création d'un paysage connu de tous, où chacun peut verser ses mémoires et ses désirs de retour (Barreiro González 2018a).

En el "Galicia y sus gentes" se condensa el patrón de representación cinematográfica que motiva toda la reflexión crítica que se abre a partir de estas líneas, así como el discurso galaiquista más representativo de toda la muestra investigada ${ }^{2}$. Desde los planos paisajísticos de un mar embravecido hasta primeros planos de cerdos y gallinas en las ferias, mujeres lavando en los ríos o haciendo la vendimia (con vestimenta sospechosamente fina: vestido, mantón y cofia), iglesias y catedrales, pastorcillos con sus cabras o ruinas atribuidas a los celtas (que en realidad son castrexas), se va construyendo un viaje costumbrista en el que en realidad no pasa nada pero la vida de la gente parece discurrir en la placidez que al franquismo de los cincuenta convenía, a pesar de que fueran años de enorme miseria y gran represión política. Solo Ferrol se salvaba de la imagen arcádica; la suerte de ser la ciudad del Caudillo.

En la tipología de Documentales NO-DO puso en marcha toda una maquinaria de verificación para producir saberes y no solo reprimir comportamientos o ideologías.

Lo que hace que el poder agarre, que se le acepte, es simplemente que no pesa solamente como una fuerza que dice no, sino que de hecho la atraviesa, produce cosas, induce placer, forma saber, produce discursos; es preciso considerarlo como una red productiva que atraviesa todo el cuerpo social más que como una instancia negativa que tiene como función reprimir (Foucault 1978: 182).

Michel Foucault, en Microfísica del poder, apuntaba la siguiente precaución en el análisis de las "grandes máquinas de poder":

Son instrumentos efectivos de formación y de acumulación del saber, métodos de observación, técnicas de registro, procedimientos de indagación y de pesquisa, aparatos de verificación. Esto quiere decir que el poder, cuando se ejerce a través de estos mecanismos sutiles, no puede hacerlo sin formar, sin organizar y poner en circulación un saber, o mejor, unos aparatos de saber que no son construcciones ideológicas (Ibid.: 146).

En los largos cuarenta años de historia cinematográfica de NO-DO el poder no solo se manifestó a través del ejercicio piramidal y absoluto del aparato de estado. Hubo otras fórmulas, otros discursos y otros ejercicios en el franquismo, de los que NO-DO también fue instrumento testimonial que el poder utilizó en la construcción de España. Fue una máquina de poder en cuanto que produjo saberes y representó culturas

Una de las estrategias fue construir discursos a través de recursos directos como la cámara en el campo, el registro de sonido, el uso de primeros planos de personas en contextos reales, planos de paisajes, el uso de nombres de lugares; todo ello con el objetivo de mostrar un documento descriptivo con un carácter veraz. Esto no quiere decir que los documentales de NO-

2 "Galicia y sus gentes. Ayer y hoy de las tierras meigas". Archivo NO-DO (Filmoteca Española): DOC BN000 (1951). Hhttp://www.rtve.es/alacarta/videos/documentales-b-n/galicia-gentes-ayer-hoy-tierras-meigas/2845926/, consultado en 2019-05-27. 
DO fuesen documentos veraces o etnográficos, puesto que los materiales están claramente dirigidos para elaborar discursos, pero sí se recurrió a estrategias más directas de registro, planos recogidos directamente sobre el sobre el terreno en el que discurría la cotidianidad de las personas, todo ello para motivar en el espectador la sensación de estar ante un documento cierto. En el documental que va a ocupar el análisis de estas páginas "los argumentos [...] son utilizados en función de los intereses del realizador, son pruebas empíricas que este incorpora para dar más fuerza y convicción a su discurso, que se presenta como objetivo y veraz" (Ardévol Piera 1995: 81).

Desde esas tecnologías de representación audiovisual se elaboró un discurso subalternizado de Galicia en el que la misma quedaba reducida a estereotipos fijados, a estampas folcloristas que construían realidades sobre ella, desde el continuum del sentimentalismo que analiza Miguélez-Carballeira hasta el uso del paisaje recreado y estereotipado que analiza Barreiro: "O imaxinario da paisaxe galega xérase coa superposición de capas de recreacións previas, propias e alleas, repetidas e ritualizadas ao longo do século XIX e XX" (Barreiro González 2018b).

Las imágenes de este tipo de documentales eran, en gran medida, tomadas en el terreno en el que se suponía que se tendrían que haber desarrollado de forma culturalmente natural: aldeas, pueblos, puertos marineros e incluso en el interior de las casas. Pero lo que muestra la imagen es una recreación inventada de lo que la realización pretendía de Galicia y lo gallego. Este tipo de documentales giraban en torno a escenarios preparados para ser registrados como supuestas situaciones improvisadas, momentos de la vida de las personas captados por la cámara en un instante, con la pretensión de ser documentos que reflejasen la realidad, cuando lo cierto es que eran recreaciones idílicas de una estampa imaginada y folclorista actuada para la cámara. Como precaución metodológica para la realización de cine etnográfico, Ardévol Piera indica:

No es aconsejable pedir a los sujetos que detengan la acción, que la repitan, que realicen ciertos actos para la cámara o que la realicen en un momento distinto al que lo hacen normalmente. No hay que intervenir en el desarrollo del acontecimiento. No a la interrupción del comportamiento, a comportamientos adecuados o a influir en el tiempo y lugar en que sucede un acontecimiento (Ardévol Piera 2006:154).

NO-DO estaba muy lejos de esa práctica cinematográfica, pero sí utilizaba el terreno para verificar y legitimar la parábola que ejecutaba sobre los pueblos que representaba.

Lo verdaderamente interesante para nosotros es analizar cómo esos discursos fijaron características culturales dinámicas en "tipos" estáticos, generando representaciones que dialogaron (y dialogan hoy) con la cultura real. En ese diálogo entre la representación y los representados se construyen realidades, puesto que aquellos y aquellas que se ven retratados se piensan a sí mismos a partir de esa representación y, del mismo modo, los y las espectadoras ajenas aprenden a pensar al otro a partir de la misma: "finalmente, la imagen que la cultura dominante construye sobre los grupos minoritarios se impone también a estos moldeando su propia subjetividad individual y la forma en que verán su propio grupo de pertenencia" (Ardévol Piera 1995: 59).

Este ejercicio de poder construye representación sobre los pueblos y esta se introduce en el discurso que el espectador o espectadora posee de esa cultura. Se trata de un mecanismo de saber/poder en el que el poder no solo opera a través de las técnicas directas del estado o de fórmulas de imposición o prohibición, sino que, a través de diferentes registros y metodologías puede producir; induce saberes como parte de su ejercicio (Foucault 2009). 
La forma en la que el franquismo, a través de los documentales de NO-DO, producía ese saber era a través de la grabación de imágenes sobre el terreno. Ese era el aparato de verificación (conjunto de prácticas discursivas y de técnicas de representación que permiten decidir lo que es verdadero de lo que es falso y así producir "saber"). El poder ejercido a través de ese método es aparentemente más sutil que aquel que obligaba a las personas, pero precisamente por eso es un ejercicio aún más perverso. NO-DO producía un documental dirigido y autoritario, no un documental etnográfico con el que las personas pudiesen dialogar. La tecnología de saber/poder de NO-DO no operaba a partir de la honestidad, sino que lo hacía a partir de la manipulación de las imágenes y de las personas que habían sido registradas figurando una cotidianidad que no era la suya.

Elisenda Ardévol recogió, en su tesis doctoral y posteriores obras suyas, la definición de lo que podríamos considerar el modelo de cine documental de NO-DO. Se correspondería con el "modelo exposicional" y lo definió de la siguiente forma:

El modelo exposicional permite la exposición de las tesis del autor sobre el comportamiento filmado o sobre conceptos abstractos como parentesco, relaciones de producción o procesos rituales. [...] se ha argumentado que este estilo es "en sí mismo" autoritario, ya que el realizador impone su discurso sobre las personas representadas en el filme. La voz y el gesto del sujeto está sometido al control del realizador (Ardévol Piera 1995: 81).

Galicia se presentaba ante las cámaras como un lugar en el que mirar la esencia del pueblo, lo primitivo y lo puro del espíritu, un pasado mítico y un carácter nostálgico y sentimental (Miguélez-Carballeira 2014). Se retrataba como un lugar en la que poder mirarse para descubrir un tiempo anterior a la temida modernidad: inalterada, virgen, inocente y que se proyectaba más allá de Galicia para la emigración, representada también como una madre que espera:

L'attente du retour de l'émigré par la mère et la terre crée un anthropomorphisme du paysage. Celui-ci devient une mère qui attend, une matrice. Rien ne peut changer dans l'imaginaire de l'émigrant, chaque modification de son village ou de sa famille devient une cicatrice émotionnelle (Barreiro González 2018a: 14).

Un pueblo humilde, laborioso, esforzado, sencillo, patriarcal, dócil, pobre pero agradecido y profundamente rural, aderezado todo ello por un mítico pasado celta puede que resultar sorprendente ya que por un lado apoyaba el argumento diferencial de la raza, pero por otra parte quedaba asimilado dentro de un destino en lo universal de mayor envergadura: España. Miguélez-Carballeira analiza profusamente ese tropo del celtismo asociado a Galicia como una herramienta discursiva de dominación colonial puesto que se construye como una representación feminizada de Galicia frente a una España masculinizada. "Assim como o mito das origens célticas ministrava as metáforas para as representações centralistas/colonialistas da identidade galega como humilde, sentimental e passiva [...]” (Miguélez Carballeira 2014: 21).

Por otra parte, el franquismo presumía tanto del espíritu guerrero de la raza, como del pasado místico, mítico y nostálgico de lo céltico. Ambas vinculaciones justificaban la dominación y el ejercicio de la violencia simbólica, puesto que ya fuese por su pasado guerrero o por su vínculo con lo femenino, Galicia debía ser sometida. Lo que Miguélez-Carballeira indica es que "o tropo do sentimentalismo galego serviu de estratégia discursiva para menoscabar um movimento nacionalista galego com vocação política potencialmente violenta” (Ibid.: 243).

La Galicia que figura en este tipo de materiales es una Galicia atemporal, una Galicia en la que el reloj del tiempo parecía haberse detenido, una Galicia Arcadia, una Galicia que parecía 
que podría haber vivido igual desde el siglo XVII hasta el siglo XX, una Galicia de postal, una estampa cultural en la que se reducía cualquier elemento cultural a una mera curiosidad "indígena" de aquellos que vivían en la franja occidental de Europa, tan acertadamente bautizada por los romanos como el Finis terrae, el final del espacio conocido y cognoscible; la frontera, donde más allá no hay nada (Murado 2013).

Para llegar a comprender cómo se construía este modelo de "cultura" en el franquismo, hay que llegar a comprender cómo se construye y cómo opera el estereotipo en la representación ajena y propia de la cultura. La obra del crítico indio postcolonial Homi Bhabha, El lugar de la cultura, es una de los más interesantes en el estudio del estereotipo y la discriminación como parte de la estrategia discursiva de lo colonial (Bhabha 2013). Bhabha mantiene que el estereotipo funciona como una estrategia discursiva de fijación de la otredad para a partir de ella y de la discriminación que se desprende, poder dominar al otro. Pablo González Casanova define este proceso de colonialismo, en el marco de un mismo estado-nación, como "colonialismo interno" y guarda estrecha relación con el proceso de colonialismo que defendemos para el estado español franquista.

[...] vemos que la colonia es: 1. Un territorio sin gobierno propio; 2. Que se encuentra en una situación de desigualdad respecto de la metrópoli donde los habitantes sí se gobiernan a sí mismos; 3. Que la administración y la responsabilidad de la administración conciernen al Estado que la domina; 4. Que sus habitantes no participan en la elección de los más altos cuerpos administrativos, es decir, que sus dirigentes son designados por el país dominante; 5 . Que los derechos de sus habitantes, su situación económica y sus privilegios sociales son regulados por otro Estado; 6. Que esta situación no corresponde a lazos naturales sino "artificiales", producto de una conquista, de una concesión internacional; y 7. Que sus habitantes pertenecen a una raza y a una cultura distintas de las dominantes, y hablan una lengua también distinta (González Casanova 2006a: 190).

También la autora Jo Labanyi, para el estudio de lo andaluz como representación estereotipada en el cine del franquismo, justifica el uso de las teorías de Bhabha en su texto explicando que el proceso de constitución nacional en la España del franquismo tiene mucho de colonial.

[...] el franquismo impuso a la nación un régimen totalitario concebido expresamente en términos coloniales; las fuerzas militares encargadas de la 'pacificación' del país fueron llamadas expresamente 'ejército de ocupación', y las ideas políticas de Franco, como él mismo reconoció, fueron aprendidas en sus largos años al mando del ejército de África. Por tanto, me parece justificable la aplicación a Andalucía (y a las otras zonas periféricas del país) de la teoría postcolonial, que se funda en la crítica del régimen colonial (Labanyi 2003: 7-8).

Resulta procedente traer la reflexión de Bhabha sobre el uso del estereotipo como herramienta discursiva de dominación colonial. En el nombre de España se tomó la parte por el todo, y así quedaron subalternizadas todas las otras partes, concebidas ya no como totalidades en sí mismas sino como parcialidades. Castilla, como icono territorial e histórico del franquismo, fue la parcialidad que adquirió dimensión total. Bajo el nombre de Castilla se subalternizó y colonizó a la Castilla misma y a las demás partes para España. Este proceso quedó aún más claro en la constitución de la España del franquismo que se fue gestando a lo largo de una Guerra Civil de tres años en la que esas fuerzas de ocupación que menciona Labanyi tenían por objetivo ir conquistando, controlando, dominando, ocupando territorios geográficos. El concepto de "colonialismo interno" de Pablo González Casanova adquiere aquí todo su sentido puesto que Castilla (y Aragón) se extendieron colonialmente en la península ibérica en la llamada Reconquista contra los musulmanes, pero también se extendieron hacia el resto de los reinos (Murado 2013). El colonialismo se llevó entonces a América a la vez que se reestructuraba el 
territorio nacional, negando la diversidad a las partes, que quedaron sometidas a la unidad; proceso que en la España franquista encontró una de sus más feroces prácticas.

Cataluña, Euskadi y Galicia venían de firmar sus estatutos nacionales a pesar de que el de Galicia no llegó a tener aplicación (fue entregado en las Cortes para su tramitación en la víspera del golpe de estado del 1936). Con el inicio de la Guerra Civil todo ese proceso quedó reprimido, al menos en el plano más superficial; los procesos de resistencia se articularon igualmente. Teniendo en cuenta esta realidad, no parece descabellado considerar que el poder que se alzaba contra la República tenía que ser capaz de establecer sus estructuras de poder y control en todas partes, es decir, ocupar e invadir territorios. Este proceso de invasión afectó a todo el territorio español, lugar por lugar. Desde este punto de vista, cualquier territorio español podría ser considerado colonia, puesto que la colonización es el paso siguiente a la ocupación. La ocupación exigió la violencia y la colonización un orden legitimado, no consensuado pero efectivo. Y por miedo, por aceptación o por costumbre, la colonización implicó el consentimiento de la dominación.

No solo fueron las tres periferias históricas las que se convirtieron en colonias invadidas del franquismo. Nuestro estudio, y este capítulo en concreto, se centra en cómo se textualizó la imagen cultural de Galicia proyectada por el NO-DO a través del uso del estereotipo y cómo este ejercicio dialogó en la construcción del estereotipo, pero si acudimos a trabajos como el de Labanyi sobre lo andaluz o como el Fandiño Pérez sobre lo riojano (Fandiño Pérez 2009) se ve que a pesar de que los indicadores varíen de un lugar a otro, la estrategia discursiva era la misma.

En esta estrategia discursiva podríamos decir que el discurso franquista es un discurso orientalista porque orientaliza los territorios. Construye una imagen/estereotipo de las partes y eso le sirve para que las culturas territoriales queden fijadas en "tipos". El trabajo de Said nos sirve para reconocer la representación del discurso franquista y mostrar cómo ese discurso ha pervivido en el tiempo (Said 2013). Por otro lado, Bhabha nos permite detallar la tecnología del estereotipo y de cómo este es apropiado y actuado por las personas, crítica y creativamente también, para reclamarle al sistema sus propias contradicciones.

La teoría de Bhabha, e incluso la influencia que ejerció en su pensamiento la reflexión de Frantz Fanon acerca del estereotipo sobre la racialidad negra (Fanon 1970), es muy interesante para comprender que a partir del cine se definía al "otro" y su otredad frente a un "nosotros", que en el caso del franquismo era una invención también, pero de lo español. Podríamos decir que ese "nosotros/los españoles" se correspondía con la tradición histórica castellana pero también era un discurso construido, ya que partía de la mitificación de un pasado histórico castellano en el que teóricamente se había constituido la nación; discurso con el que nadie, ni los castellanos, llegaban a identificarse del todo, aunque pretendiese tener efectos de verdad. En cualquier caso, los gallegos eran unos de tantos "otros" a los que había que asimilar bajo ese nuevo modelo de estado que al principio se centró en ser una cruzada cristiana y anticomunista y posteriormente en un imperio desarrollado capitalista. El estereotipo servía para establecer la relación de dominación y el discurso de la raza céltica justificaba el ejercicio de tal dominación. Para Homi $\mathrm{K}$. Bhabha, el estereotipo es una manera de manejar lo heterogéneo, el temor a esa diferencia y para ello la fijación de esa realidad compleja facilita su dominación, pero también provoca la propia ambivalencia de la diferencia y, con ella, la resistencia. De este retrato surge no solo el estereotipo en sí mismo sino la sensación de atemporalidad, de congelación que se vivía en el NO-DO cada vez que un pueblo quedaba inmortalizado en las imágenes. 
Un rasgo importante del discurso colonial es su dependencia del concepto de "fijeza" en la construcción ideológica de la otredad. La fijeza, como signo de la diferencia cultural/histórica/racial en el discurso del colonialismo, es un modo paradójico de representación: connota rigidez y un orden inmutable, así como desorden, degeneración y repetición demónica. Del mismo modo el estereotipo, que es su estrategia discursiva mayor, es una forma de conocimiento e identificación que vacila entre lo que siempre está "en su lugar", ya conocido, y algo que debe ser repetido ansiosamente... (Bhabha 2013: 91).

En este ejercicio de colonización en el que la otredad quedaba representada en estereotipos, a través de este proceso de fijación y repetición, el discurso dialogaba directamente con lo que cada uno sabe sobre sí mismo y lo que es (Barreiro González 2018a). No es un simple discurso de dominación que se ejerce sin llegar del todo a operar o construir, sino que el estereotipo se llega a asimilar de manera colectiva de alguna manera. Miguel-Anxo Murado en su Outra idea de Galicia desarrolla un completo ejercicio sobre cómo, cuándo y a partir de qué indicadores se construyó esa idea de Galicia estereotipada y fosilizada en tipos. Su libro fue pensado para deconstruir esa idea de Galicia tópica fuera de las fronteras de la Galicia misma pero lo cierto es que cualquier gallega o gallego vive relacionándose con esos estereotipos en su vida cotidiana, por lo que su lectura se presenta útil para para pacificarse en la actualidad. La grave incomodidad que genera el estereotipo, así como la autoimagen negativa sobre uno mismo, es una evidencia que no se puede ni debe negar, en el caso de Galicia. Murado también pone de manifiesto como esa idea construida no está basada en elementos inciertos de la cultura sino en un reduccionismo y folclorismo tipista de elementos culturales que pueden ser ciertos. Si no fuese así, el ejercicio violento del poder no operaría con la misma eficacia. Los adjetivos calificativos que describen el estereotipo se encuentran reunidos en $\mathrm{NO}-\mathrm{DO}$ con indudable certeza: rural, agraria, esencial, primitiva, hermosa, sencilla, esforzada, humilde, pobre, ganadera, patriarcal, antigua, vieja, cristiana, céltica, mística, ritual, misteriosa, meiga, supersticiosa, alegre, desconfiada, generosa, productiva, conservadora, céltica, virgen; todos o casi todos los que trata Murado en su libro. Del mismo modo, los verbos son categóricamente definitorios, el más explícito: el verbo ser. Así, Galicia “es” y los gallegos “son” con absoluta insistencia.

Al conjunto de estas representaciones de "lo gallego" nos hemos referido como galaiquismo, siguiendo las tesis de representación de Edward Said en Orientalismo (Said 2013). Un discurso que nace de la mirada exótica de occidente (España) sobre un oriente (Galicia) que no se corresponde con una realidad geográfica o cultural concreta. Una representación que se desarrolla a partir de la mirada reproducida, fijada y repetida por viajeros, aventureros, turistas, escritores románticos, pintores, la literatura; alimentada desde diferentes áreas de representación cultural. Orientalismo sería el espacio imaginario de representación occidental sobre otro concepto occidental difuso, "el Oriente". Esta mirada esencializada de lo "otro" se dio también en relación a "lo español" y a la mirada de los extranjeros y viajeros del siglo XIX (MiguélezCarballeira 2014). Una representación ambigua que se movía entre lo exótico y lo temible. Una colección iconográfica de "tipos" ridiculizados que ya se veían en la literatura de Lope de Vega o Francisco de Góngora o en el teatro escénico que se representaba en los teatros de Madrid en los que "el gallego" y/o "la gallega" a menudo eran representados como tipos cómicos, ridiculizados cuya función teatral era, básicamente, provocar risa; "en resumo, a imaxe de Galicia en España non a construíron escritores galegos, e é por iso que resulta tan típica, incapaz de saír do que poderiamos chamar os tres elementos primordiais: o verde da herba, o azul do mar e a transparencia da chuvia" (Murado 2013: 47) . Posteriormente, basta revisar la cartelería turística del siglo XX que hace referencia a Galicia, o la colección de postales, analizar las campañas publicitarias televisivas como por ejemplo Galicia, o bo camiño, entrar en una tienda de souvenirs o pasearse por el stand de Galicia en el FITUR, para comprender como ese ejercicio folclorista se 
está reproduciendo en la más absoluta actualidad, contribuyendo a la prolongación de un modelo de exportación turística basado en imágenes estereotipantes que tienen un gran impacto cultural-negativo — en las comunidades locales.

Del mismo modo, lo que hemos dado en llamar galaiquismo, es el conjunto de representaciones basadas en los estereotipos y "tipos" de lo gallego, constantemente bautizado como galaico por NO-DO formando una representación imaginaria de Galicia producida fuera de ella. El galaiquismo en el discurso de NO-DO funciona como representación cultural de Galicia y bajo su paraguas se suceden los estereotipos que el régimen pretendía de lo gallego en un doble objetivo de dominación: por un lado, reducir a un tipo fijado y folclórico la diferencia cultural que pudiera existir como subversiva al proceso de españolización del país. Por otro lado, mostraba un prototipo cultural adecuado a los valores que el franquismo pretendía como válidos y adecuados para todos y, sobre todo, para todas las españolas: humildad, laboriosidad, esfuerzo, cristianismo y obediencia.

Todo este proceso de representación producía en el espectador ajeno a Galicia una imagen cultural que podía creer cierta, ya que NO-DO, como se ha visto, utilizaba la cámara insertada en el campo como registro de verificación (Ardévol Pierra 1995), produciendo una imagen de Galicia que posteriormente se utilizó con fines comerciales y turísticos. Por otra parte, ese proceso de producción afectó también a la imagen que tenía Galicia de sí misma, como si de un perturbador espejo se tratase. Los y las gallegas empezaron a pensarse a sí mismos, sobre todo por rechazo, a partir de estas representaciones. "El contexto colonial [...] se caracteriza por la dicotomía que inflige al mundo" (Fanon 2018: 47). En este sentido el poder, en términos políticos, se difuminó notablemente del poder del aparato de estado ejercido de manera directa. El poder en este caso se centró en la producción de saberes y conocimientos culturales sobre los "otros" aunque eso implicase la creación de "tipos" culturales inventados. Esa invención tenía un carácter claramente político pero su eficacia fue notablemente mayor ya que a partir ella los estereotipos se producían y reproducían en el seno del colonizado y el ejercicio de poder y de dominación pasó a estar en manos de todos y todas, construyendo esas mismas realidades.

Esa diferencia renegada y enmascarada de lo galaico aparece bajo términos contradictorios en los materiales documentales de NO-DO, en donde el discurso del galaiquismo se produce y manufactura en los estudios madrileños del organismo a través de un tipo de documental dirigido, autoritario y en donde las personas aparecen representadas como "tipos" con una que no es la suya.

La relación del realizador con los sujetos que filma en el modelo expositivo es de total control por parte del primero sobre el discurso y acciones de los segundos. La voz narradora es incuestionada, guía al espectador, se impone sobre la voz de los sujetos representados e indica como deben ser interpretados (Ardévol Piera 1995: 81).

Sus imágenes, locuciones, la banda sonora, el montaje, el tipo de planos, la producción y todos y cada uno de los peldaños que intervienen en la creación audiovisual se conjugaban para producir un retrato cultural tipificado, mostrando a los pueblos a través de una "otredad" que había que digerir como fuese. Y ese discurso galaiquista, al construir relatos sobre la realidad, se insertó en el individuo quien lo puso en circulación, a través de la repetición de ese mismo estereotipo y de su consumo turístico. 
El poder de estado logró, con esa asimilación cultural, resignificar la diferencia cultural convirtiéndola en una diferencia colonial entre centro y periferia-lo que Miguélez-Caraballeira menciona como centralismo/colonialismo-pero además utilizó esa diferencia subalternizada administrándola como un mal menor para que aquellos y aquellas que pudieran sentirse diferentes se viesen representados en esa "diferencia suya". El uso de la lingua galega, por ejemplo, funcionaba en NO-DO como una dosis controlada de "veneno" (nacionalismo periférico). En cualquier caso, ni aquel pueblo sentimental ni su idioma poético/rosaliano fueron considerados potencialmente peligrosos. Por eso NO-DO se permite la licencia de mencionar explícitamente a Rosalía de Castro. Todo era nostalgia y docilidad y el idioma fue un parámetro claro de feminización de Galicia frente a la masculinización de España y del español.

Diversas imagens duma Galiza feminina -ou feminizada-, umas terras caracterizadas pela sua misteriosa lonjura, pela natureza passiva e melancólica das suas gentes e pelas qualidades doces e poéticas da sua língua, aparecem de modo recorrente em textos históricos, literatura de viagens, crítica cultural, textos literários e em tantos outros géneros em que a identidade nacional galega foi descrita ou teorizada (Miguélez-Carballeira 2014: 243).

NO-DO hizo uso explícito da lingua galega en sus documentales, presentándola como una curiosidad rural asociada, por un lado, a lo aldeano y analfabeto-por lo que se alimentó el estigma negativo del idioma; estigma que sigue vivo hoy en día-y, por otro lado, se presentó como una curiosidad lingüística propia de un pueblo sentimental, nostálgico y choromiqueiro. El idioma, en cualquier caso, aparece reducido a su ámbito oral puesto que este se vincula con el mundo rural y arcádico mientras el castellano-la lengua de estado-se presenta como una lengua letrada y, por lo tanto, con derecho a su forma escrita.

El hecho de utilizar el idioma también responde a una manera de gestionar la contradicción a través de la desactivación por apropiación. El uso del idioma no parecía resultar tan agravante ni peligroso como el uso del catalán o el vasco, ya que estas lenguas parecían poseer una significación política que el régimen no percibía en el caso de Galicia, seguramente por el hecho de que lo hablasen "los gallegos de las aldeas". El vasco y el catalán representaban más modernidad que el gallego, puesto que tanto Euskadi como Cataluña estaban notablemente industrializadas y modernizadas y Galicia teóricamente no; Murado desmiente este mito del atraso industrial en Galicia con indiscutible claridad (Murado 2013: 131-145). El uso de un idioma diferencial del castellano que pudiera vincularse al progreso no convenía. Sin embargo, el uso de un idioma vinculado a la arcadia podía ser fácilmente asumible, gestionado y a través de su uso desactivado; incluso resultaba procedente en esa representación feminizada, pastoril, poética y atrasada. A esto se sumaba el hecho de que los gallegos tampoco parecían resultar peligrosos en demasía debido al carácter afable, silencioso y rural que el régimen les atribuía. Ni el gallego como idioma, ni el gallego como individuo, ni el galeguismo como movimiento, ni Galicia como territorio eran percibidos por el franquismo como subversivos, como sí lo eran otros movimientos vinculados a Cataluña o Euskadi, así que el uso de su diferencia era incluso procedente y adecuado. Si bien es cierto que el insistente maltrato de Galicia por parte del régimen evidenciaba un temor no manifiesto en el discurso de la imagen.

La lengua deja de serlo para convertirse en fala de esos personajes pintorescos que los planos muestran. Esa fala se presenta como un indicativo más de personajes tipificados; un recurso teatral costumbrista. Tal ejercicio de tipificación está profundamente relacionado tanto con el ejercicio de verificación como con el de la tipificación, pues se opera a través del lenguaje y de la asociación que se hace del mismo con las personas. El hecho de que se asignen diálogos, fra- 
ses y pensamientos a los seres que se ven en plano expresados en su lengua, pretende dotar a la imagen de un carácter documental o testimonial, estrategia que queda establecida a través de la imagen y de su evidente presencia en un escenario real. Por lo tanto, el discurso, en ese lenguaje audiovisual pseudoetnográfico, pretende quedar verificado a través de los diálogos asignados a las personas que se presentan en el plano a pesar de que sean inventados y leídos por personas que no formaban parte de la realidad que el espectador observaba en el cine. Esos diálogos se desarrollaron a través de la fala de "esas gentes" como una estrategia más de confirmación. E1 idioma se fijó como constatación de otra curiosidad más de las tantas presentadas desde una óptica folclorista; un elemento más en la estampa galaica de NO-DO.

Por último, el poder opera también porque dirige la voz de los que no tienen derecho a pronunciarla por sí mismos. Habla por ellos y ellas, por lo que se trata de una voz arrebatada. Esta apropiación que se hace de la voz de los que no tienen derecho a ella nos lleva a reflexionar sobre la pregunta que se hacía Spivak al respecto de si pueden o no hablar los subalternos. Esa situación de sometimiento está atravesada también por cuestiones de género. El subalterno no solo no tiene voz, sino que la misma le es robada para decir cosas que seguro no hubiera dicho si le hubieran dado la ocasión de hablar por sí mismo. La subalterna tampoco tiene voz y tiene aún menos derecho a ella por ser mujer. La campesina no tiene voz propia y su voz también le es robada para poner en su boca diálogos relacionados con el universo de lo doméstico, de lo poético, de lo sentimental, que es el suyo, según el discurso hegemónico. La violencia simbólica que se produce de tal apropiación muestra un ejercicio perverso del uso de la palabra y, por supuesto, del uso del lenguaje y del idioma, ya que el "robo" se produce, precisamente, a través de un idioma también subalternizado frente al castellano, no solo a nivel simbólico, sino también a nivel jurídico.

Spivak apuntaba que dar por hecho que el subalterno puede hablar en cualquier situación era mucho considerar, puesto que las condiciones de posibilidad para hablar no siempre se producen (Spivak 2009). A los gallegos y gallegas representados en el NO-DO no se les concedió la posibilidad de hablar. No sabemos si las personas que fueron grabadas en los planos de NODO pudieron haber dicho algo; lo que fuese. Quizá, de haber podido hablar, hubieran dicho otra cosa distinta a: "O grano éche ben gordo!" mientras otra le respondía: “¿E que querías?, ¡Nesta terra canto se cría é bo!”’ . Quizá hubieran preferido estar en silencio y, de haber hablado, seguramente lo hubieran hecho en español, evitando ante la cámara un idioma que NO-DO les asignaba pero que la escuela franquista les enseñaba a despreciar y rechazar (Castelao 1961, Costa Clavell 1977, Cardesín Diaz 2005). En cualquier caso, hablan no teniendo voz porque otros han considerado hacer uso de su voz, de su idioma y de su entonación en un ejercicio de tipismo, estereotipia y verificación al servicio del discurso del documental. Es evidente que no puede haber etnografía en un documental en el que se inventa y asigna una voz a otro ser.

El documental "Galicia y sus gentes" mostraba aquel pueblo del noroeste que, en lugar de quejarse, trabajaba, rezaba, reía y cantaba y bailaba muiñeiras por los prados verdes de aquella primitiva región que conservaba en un estado tan puro el verdadero espíritu de lo que debía ser España.

3 Diálogo inventado entre dos mujeres mientras se ven planos de una feria de ganado y productos agrarios, en algún lugar no determinado. Minutaje 00:14:35 a 00:14:40. 
Como cierre a 59 minutos de metraje subalternizador y sonando de fondo el Negra Sombra de Rosalía de Castro (en esa idea feminizada, poética, dócil, sentimental, nostálgica y choromiqueira de Galicia), con el arreglo musical de Juan Montes y planos de un cielo con nubes y claros sobre un mar en calma que se ven interrumpidos por la silueta a contraluz de una campesina pasando por delante de la cámara con su carro de bueyes, esta era Galicia para NO-DO:

Galicia eterna, muestra en su cielo Jacobeo nubes de Gloria. En sus hórreos se exalta el valor del hombre que trabaja amorosamente la tierra y que, a ella, y a la religión y al cariño de sus mayores, sigue unido a través de todos los azares y aventuras, por encima de la distancia y el mar; nostálgicamente, en los duros trabajos y en el pan amargo de la emigración, o en la hora del Triunfo y de la Victoria. Esta es Galicia: tenaz, silenciosa, callada, profundamente mística y finamente alegre; ejemplo y prez de la España inmortal ${ }^{4}$.

\section{Bibliografía}

Ardévol Piera, Elisenda. 1995. La mirada antropológica o la antropología de la mirada. [Tesis doctoral dirigida por el Dr. Alexander Moore.] Bellaterra (Barcelona), Publicacions de la Universitat Autònoma de Barcelona.

.2006. La búsqueda de la mirada. Antropología visual y cine etnográfico. Barcelona, Editoral UOC.

Barreiro González, Ma Soliña. 2018a. "Paysage et émigration: une anthropologie visuelle de l'espace galicien dans le cinéma du réel" en Journées jeunes chercheurs en Geographie sociale. Université Rennes II, 19-20/03/2018. Disponible en https://www.academia. edu/36595670/Paysage_et_\%C3\%A9migration_une_anthropologie_visuelle_de_lespace_galicien_dans_le_cin\%C3\%A9ma_du_r\%C3\%A9el, consultado en 2019-05-27.

2018b. "Filmar a terra. A paisaxe como cuestión de clase", en Marcas na paisaxe, pp.4380. Vigo, Editorial Galaxia.

Bhabha, Homi K. 2013. El lugar de la cultura. [Edición original en inglés, 1994]. Buenos Aires, Manantial.

Castelao, Alfonso R. 1961. Sempre en Galiza. Buenos Aires, Edición “As Burgas”.

Costa Clavell, Xavier. 1977. Las dos caras de Galicia bajo el franquismo. Madrid, Editorial Cambio. Fandiño Pérez, Roberto Germán. 2009. La Rioja al alcance de todos los españoles. NO-DO y la construcción de un discurso sobre la provincia. Logroño, Gobierno de la La Rioja/Instituto de Estudios Riojanos.

Fanon, Frantz. 1970. "Racism and culture", en Toward the African Revolution, traducido por H. Chevalier, pp.29-44. Londres, Pelican.

2018. Los condenados de la tierra. [Edición original en francés, 1961]. Ciudad de México, Fondo de Cultura Económica.

Foucault, Michel. 1978. Microfísica del poder. Madrid, Las Ediciones de La Piqueta. 2009. El gobierno de sí y de los otros. Curso en el Collège de France (1982-1983). Buenos Aires, Fondo de Cultura Económica de Argentina.

González Casanova, Pablo. 2006a. "El colonialismo interno", en Sociología de la explotación, pp. 185-205. Buenos Aires, CLASCSO. Disponible en http://bibliotecavirtual.clacso.org.ar/ ar/libros/secret/gonzalez/colonia.pdf, consultado en 2019-05-27.

$4 \quad$ Locución final del documental "Galicia y sus gentes. Ayer y hoy de las tierras meigas”. DOC BN 000 (1951). Minutaje: 00:56:40-00:58:16. Hhttp://www.rtve.es/alacarta/videos/documentales-b-n/galicia-gentes-ayer-hoy-tierras-meigas/2845926/, consultado en 2019-05-27. 
.2006b. “Colonialismo interno (una redefinición)”, en La teoria marxista hoy. Problemas y perspectivas, pp. 409-434. Buenos Aires: CLACSO.

González-Millán, Xoán. 2000. Resistencia cultural e diferencia histórica: a experiencia da subalternidade. Santiago de Compostela, Sotelo Blanco

Labanyi, Jo. 2003. Lo andaluz en el cine del franquismo: los estereotipos como estrategia para manejar la contradicción. Sevilla, Fundación Centro de Estudios Andaluces. Disponible en https://es.scribd.com/document/353262154/Labanyi-Lo-Andaluz-en-E1-Cine-DelFranquismo, consultado en 2019-05-27.

Miguélez-Carballeira, Helena. 2014. Galiza, um povo sentimental? Género, política e cultura no imaginário nacional e galego. Santiago de Compostela, Através editora.

Murado, Miguel-Anxo. 2013. Outra idea de Galicia. Barcelona, Debate.

Said, Edward W. 2013. Orientalismo. [Edición original en inglés, 1978]. Barcelona, Debolsillo. Spivak, Gayatri Chakravorty. 2009. ¿Pueden hablar los subalternos? Traducido y editado por Manuel Asensi Pérez. [Edición original en inglés, 1985]. Barcelona, Museu d'Art Contemporani de Barcelona.

Tranche, Rafael R. y Sánchez-Biosca, Vicente. 2006. NO-DO. El tiempo y la memoria. Madrid, Cátedra/Filmoteca Española.

1993. "NO-DO. El tiempo y la memoria." En Cuadernos de la Filmoteca, I. Madrid, Filmoteca Española.

\section{The Architecture of the Cultural Stereotype in Francoist Regime CINEMA: THE "Galaiquism"}

"Galaiquism" is a term inspired by the concept of "Orientalism"- proposed by Edward W. Said-that we use to reflect on how NO-DO, the cinematographic propaganda apparatus of Francisco Franco's regime, generated a discourse about the cultural representation of Galicia and its identity, through the folklorization of its culture. Many NO-DO materials make explicit reference to folklore, elaborating a territorial map within which stereotypes were used as signs of cultural representation, and invention became an important tool for the promotion of tourism. NO-DO turned into a powerful device for the regime, producing a discourse which was executed from the "outside" towards the "inside", exercising power vertically and expressing culture by means of folkloric prints which represented the colonial gaze from the centre towards the peripheries, denying the people portrayed the possibility to question the allegory that was produced on their behalf.

Keywords: folklorism, power, representation, ethnicity, cinema

Data recibido: 2017-08-23

Data aceptado: 2018-03-05 